\title{
Análise crítica em organizações sociais: apropriando teoria e prática de seus componentes estruturais e culturais
}

\section{Critical analysis of social organizations: an overview of its cultural and structural elements}

Leane Mota Araujo dos Santos, MSc ${ }^{1}$

Fernando Dias Lopes, Dr²

Miguel Eduardo Moreno Añez

\section{Resumo}

As organizações sociais encontram-se em expansão e em reconhecimento por parte do governo e da sociedade, mas ainda carecem de estudos acadêmicos a partir das práticas da sua dinâmica organizacional. 0 propósito deste artigo é analisar as particularidades da gestão das ONGs no que concerne aos aspectos culturais e estruturais, identificando se os elementos encontrados se apresentam de forma congruente com o que se espera de uma ONG. Dessa forma, busca contribuir para a análise crítica à transposição inapropriada de conceitos da teoria organizacional tradicional para a gestão das ONGs e, também, para o delineamento de um arcabouço teórico específico para a compreensão dessas organizações, considerando a realidade nacional. A pesquisa foi conduzida em 10 ONGs, com abordagem predominantemente qualitativa. Os dados foram coletados através de entrevistas com os fundadores e/ou principais dirigentes das ONGs. Os resultados confirmam as particularidades identificadas em estudos anteriores e avança à medida que faz uma análise crítica e revela congruências com relação à cultura e incongruências referentes à estrutura social, principalmente, quando da utilização acrítica de instrumentos das organizações tradicionais.

Palavras-chave: Organização não Governamental. Estrutura Organizacional. Cultura Organizacional.

\begin{abstract}
The social organizations have been acknowledged as important actors by both government and civil society. However, it is necessary to develop academic studies for comprehending its organizational dynamic. This paper aims to analyze the management specificities of this kind of organization, focusing on its cultural and structural elements. Besides, it was analyzed the congruence between these elements and the expectation about NGO's dynamic and performance. In this sense, it seeks to contribute to a critical analysis of the employment of traditional organizational theory's concepts in an inappropriate way for understanding NGOs. The research was carried on in ten NGOs with a predominantly qualitative approach. The data were collected through interview with the founders and managers of these organizations. The results confirm the particularities already identified in other studies and goes beyond by doing a critic concerning to the incongruence related to social structure. The incongruence between social structure and the nature of this kind of organization is more frequently when NGO's managers employ practices of economic organizations without consider theirs fundamental assumptions.
\end{abstract}

Keywords: Non Governamental Organization, Organizational Structure, Organizational Culture

\footnotetext{
${ }^{1}$ Mestre em Administração pela Universidade Federal do Rio Grande do Norte - UFRN. Professora da Faculdade de ciências, cultura e extensão do Rio Grande do Norte - Endereço: Rua Dr. Manoel A. B. Araújo, 116, ap 103, Ponta Negra, Natal, RN - Brasil - Cep: 59090430. E-mail: leanemaraujo@gmail.com

${ }^{2}$ Doutor em Administração pela UFRN. Professor do Propgrama de Pós-Graduação em Administração da Universidade Federal do Rio Grande do Norte PPGA/UFRN. Endereço: Rua Visconde de Abaeté, 1653 Capim Macio - Natal - RN - Brasil - CEP 59082-480. E-mail: fdlopes2001@yahoo.com.br

${ }^{3}$ Pós-Doutor em Administração Internacional pela HEC-Montreal-Canadá, Doutor em Administração pela EAESP-FGV, Professor do PPGA/UFRN. Endereço: Rua Rodrigues Alves, 1271 - apto 302 Natal-RN-Brasil CEP 59020-200 - E-mail: anez21@ hotmail.com anez1957@yahoo.com.br

Artigo recebido em agosto de 2006 e aceito para publicação em outubro de 2006
} 


\section{Introdução}

Os estudos dentro da teoria administrativa e da teoria organizacional têm derivado principalmente de estudos empíricos em organizações burocráticas e voltadas para resultados econômicos. Observa-se como dominante nos estudos das organizações a visão de racionalidade como cálculo utilitário das conseqüências, reduzindo-se assim a ação administrativa como ação social no que concerne a sua orientação para fins ou resultados. Esse viés instrumental na construção das teorias administrativas tem levado ao desenvolvimento de tecnologias de gestão de difícil assimilação para organizações centradas numa ação de caráter mais valorativo, como é o caso das organizações sociais ou organizações do terceiro setor.

Nas últimas décadas tem sido crescente a presença das ONGs no cenário nacional e internacional. Diante desse crescimento também pode se verificar um aumento exponencial do número de artigos e outras formas de publicações sobre sua gestão. Porém, devido à carência de um arcabouço teórico específico para a compreensão das ONGs, muitos desses estudos têm como característica uma mera transposição de conceitos da teoria organizacional tradicional para explicar sua gestão. Ao não refletir sobre os fundamentos epistemológicos dessas abordagens teóricas ou sobre a aplicabilidade diante da realidade nacional, os estudos acabam por empregar conceitos inapropriados às características e especificidades dessas organizações.

Alguns pesquisadores têm evidenciado um conjunto de expectativas relativas à gestão de ONGs, tais como a presença de líderes idealistas e comprometidos, processo decisório participativo e estruturas flexíveis (ROESCH, 2002). Outros autores têm afirmado sobre a necessidade de se construir modelos alternativos de gestão que tomem como base o conceito de racionalidade substantiva proposta por Ramos (1989), ao mesmo tempo em que alertam para o fato de que o funcionalismo desvirtua o foco de interesse comunitário (ANDION, 2005; MEIRA; ROCHA, 2003; SERVA, 1996; TEODÓSIO, 2001).

Partindo dessas considerações, esta pesquisa tem como problema a seguinte questão: As particularidades referentes aos aspectos culturais e estruturais das organizações sociais são congruentes com relação ao que se espera da gestão desse tipo de organização? E como objetivo este estudo se propõe a analisar as particularidades da gestão das ONGs no que concerne aos aspectos cultura e estrutura. Assim, a partir dos dados empíricos, foram identificadas características culturais e estruturais e como esses elementos se apresentam de forma incongruente ou congruente com o que se espera de uma ONG. Finalmente, o estudo apresenta um conjunto de considerações sobre os limites das práticas de gestão vigentes nas organizações estudadas e propõe novas questões de pesquisa para a área.

A primeira parte do artigo apresenta uma revisão sobre gestão de ONGs e terceiro setor. A segunda parte discute os conceitos de estrutura e cultura. A terceira parte apresenta as organizações estudadas e suas particularidades, bem como a respectiva análise. Finalmente, serão apresentadas as conclusões e recomendações.

\section{Terceiro setor e gestão de organizações sociais}

A crise do Estado de bem-estar social, aliada a outros fatores, tais como o desemprego, a globalização e o aumento das desigualdades sociais, provocou mudanças nas relações entre cidadãos e governo, assim como alterações na configuração da sociedade civil, culminando com o surgimento de novas instituições sociais, a abertura de novos canais de reivindicações sociais e a emergência de organizações do terceiro setor - as organizações sociais.

Desde a década de 1990, as organizações do terceiro setor vêm apresentando um crescimento significativo. O Instituto Brasileiro de Geografia e Estatística (IBGE), o Instituto de Pesquisa Econômica Aplicada (Ipea), a Associação Brasileira de Organizações Não-Governamentais (Abong) e o Grupo de Institutos, Fundações e Empresas (Gife) lançaram pesquisa revelando que o crescimento das organizações do terceiro setor é maior a cada década (Brasil, 2005). 
Nas últimas duas décadas, ocorreram transformações no contexto das organizações sociais, sendo uma das mais fortes, o redirecionamento do foco das instituições financiadoras para outros países. Isso provocou a necessidade de ajustes na estrutura e na forma de atuação das organizações sociais, revelada através de uma busca constante pela profissionalização e capacitação para atuarem como prestadoras de serviços e parceiras do Estado, de instituições do mercado ou de outras instituições do terceiro setor. Ocorre, assim, a transição de uma organização voltada para a mobilização social para uma organização voltada para a realização de projeto social mais amplo e direcionado, extremamente preocupada com a sustentabilidade.

Algumas pesquisas realizadas na área de gestão social vêm demonstrando a utilização de teorias e técnicas convencionais na análise e administração das organizações sociais e destacando sua inadequação (BRUM; ASSIS; COSTA, 2004) ou os cuidados que se deve ter ao utilizar modelos tradicionais, de modo a manter o caráter original dessas organizações (MATTOS; DINIZ, 2002).

Em contrapartida, livros publicados sobre gestão de ONGs seguem uma linha diferente daquela encontrada nas pesquisas de campo. Tenório (2003) faz uma adaptação das funções gerenciais - planejamento, organização, direção e controle - para a realidade das organizações não-governamentais. Takeshy (2002), em publicação sobre ONGs e terceiro setor, enfoca mais estudos sobre o terceiro setor e a responsabilidade social que especificamente sobre gestão de ONGs, enquanto Hudson (1999) fundamenta seu texto na sustentabilidade das ONGs.

Em pesquisa sobre estrutura das ONGs, Brum, Assis e Costa (2004) refletem sobre a possibilidade dessas organizações estarem trabalhando de forma equivocada quando se trata da estrutura organizacional diante do ambiente onde atuam. Mas apesar disso, ressaltam que há grande motivação e alto nível de consciência quanto à visão, missão organizacional e valores, ao contrário do que ocorre em organizações burocratizadas.

Portanto, encontram-se pessoas motivadas e comprometidas com uma missão institucional voltada para o social, porém desenvolvendo seu trabalho através de uma estrutura incoerente com o ambiente onde atua e com as estratégias sociais que praticam. As organizações sociais estariam assim se estruturando e profissionalizando segundo os moldes das organizações tradicionais, sem levar em conta especificidades da sua gestão e sua essência substantiva, que pressupõem estruturas flexíveis, trabalho em equipe, pouco grau de formalização, de padronização e hierarquização. Uma explicação para isso poderia ser buscada na teoria institucional, a qual vai mostrar a força com que pressões políticas, sociais e culturais no ambiente (pressões isomórficas) conduzem as organizações à adoção de estrutura e formas de ação cada vez mais homogêneas como recurso à sobrevivência (MEYER; ROWAN, 1991; POWELL; DIMAGGIO, 1991).

Segundo Roesch (2002), quando do surgimento das organizações sociais, o modelo administrativo utilizado era o eclesiástico, passando para o estatal, e atualmente a tendência é a adoção de modelos de gestão empresarial. Com relação à transição para adoção dessa tendência, Mattos e Diniz (2002) realizaram pesquisa sobre os reflexos das mudanças (fundamentadas em modelos de gestão empresarial) nas referências originais das ONGs, na alteração conceitual e na diminuição da importância do projeto original ou seu abandono. Resultados da pesquisa demonstraram que $66 \%$ das ONGs sofreram algum tipo de alteração e que somente em $34 \%$ houve permanência inalterada da referência original.

Ainda nessa pesquisa, entre as referências mais alteradas, tem-se a orientação ideológica, idéias desenvolvimentistas, igualdade e gestão democrática, havendo o abandono de uma delas, a informalidade. Com relação à cultura organizacional, foi verificada uma substituição dos valores originais típicos das organizações sociais altruísmo, promoção social, ajuda mútua, compaixão, voluntarismo, sensibilidade, solidariedade, direito à livre expressão e organização - por valores de mercado: competição, excelência empresarial, profissionalismo, individualismo, pragmatismo, foco nos clientes, eficiência e eficácia (ROESCH, 2002). Percebe-se então a existência de elementos da racionalidade substantiva. Porém, estes vêm sendo cada vez mais substituídos por elementos da racionalidade instrumental.

De acordo com Meira e Rocha (2003), há casos de adoção do funcionalismo bem-sucedidos, mas para a implantação sempre existe um amplo processo de avaliação, envolvendo intenso debate interno com participação, envolvimento, discussão e comunicação. Portanto, há a possibilidade de uso dos modelos tradicionais, mas 
desde que sua implantação seja guiada mais por elementos da racionalidade substantiva que pelos da instrumental, conforme proposto por Ramos (1989).

Em outra pesquisa sobre tendências na gestão das ONGs, Mendes (1997) analisou a força motriz das ONGs como fator determinante básico para os limites da utilização dos modelos e técnicas de gestão, verificando a relação existente entre as mesmas.

Mattos e Diniz (2002) identificaram algumas ironias relativas à apropriação, por parte das organizações sociais, de modelos da administração tradicional: o acesso ao mundo do gerenciamento através de leitura dos gurus da administração tradicional e internacional sem questionar a coerência com o contexto específico e a realidade regional ou nacional; a adoção de estilos já ultrapassados na administração tradicional e o fato de que teorias em vigor abordam processos já existentes nas organizações sociais pela própria natureza das mesmas, como trabalho em equipe, compartilhamento de informações, redução hierárquica e aprendizagem organizacional.

Melo, Fischer e Soares Jr. (2003), em estudo sobre a diversidade e confluências no campo do terceiro setor, corroboram a existência da diversidade organizacional e identificaram confluências relacionadas ao fato de que essas organizações atuam em mais de uma área e de que a maioria atua em parceria com outras organizações, denotando uma busca pela ação integrada e pela interdisciplinaridade. Essa caracterização demonstra, mais uma vez, a necessidade de flexibilidade nas estruturas organizacionais.

De acordo com Marçon e Escrivão Filho (2001), gestão social representa o conjunto de processos sociais no qual a ação gerencial se desenvolve por meio de uma ação negociada entre seus atores, reduzindo o caráter burocrático em função da relação direta entre o processo administrativo e a múltipla participação social e política. Assim, a gestão social se pretende em permanente construção, não assumindo, portanto, caráter normativo. Tenório (2003) destaca como aspectos fundamentais da gestão social a participação, o processo decisório coletivo e a lógica da solidariedade comunitária.

As organizações sociais apresentam particularidades na sua caracterização e gestão que justificam a necessidade de estudos específicos e o desenvolvimento de técnicas e teorias próprias de gestão. São particularidades dessas organizações: atuação com foco no desenvolvimento de projetos e parcerias; elevado grau de relacionamento interorganizacional; estrutura administrativa complexa, caracterizada pela diversidade e dificuldade de quantificar objetivos e monitorar o desempenho organizacional; dificuldade de planejamento prévio e voluntariado. Outras particularidades estão diretamente relacionadas à cultura e seu processo de construção: clima organizacional com igualdade e direito de participação de todos; trabalho motivado por ideal compartilhado, objetivando a auto-realização dos membros; pessoas identificadas com a missão, que representa o principal aspecto motivador da organização; maior compartilhamento das informações; informalidade e tomada de decisões coletiva (ANDION, 2005; MARÇON; ESCRIVÃO FILHO, 2001; MELO; FISCHER; SOARES JR., 2003; TEODÓSIO, 2001).

Diante das especificidades da gestão das organizações sociais e da falta de fundamentos sistematizados, prática e teoricamente, observa-se a existência de confusões, generalizações inadequadas e contradições. A partir desse quadro, Roesch (2002) apresenta como desafios da gestão dessas organizações: o profissionalismo; o conflito entre idealismo e flexibilidade em contraponto à ordem hierárquica; a participação e qualidade em prover serviços como dependentes da visão e comprometimento pessoal dos líderes; e o estabelecimento de parcerias versus a perda da autonomia, gerando desconfiguração do caráter original das organizações sociais.

O desafio da profissionalização diante das especificidades das ONGs é analisado por Pinheiro (2003), quando coloca que o caráter social dessas organizações suscita a necessidade de uma administração competente, que compreenda os elementos sociais e sua importância e os mantenha como partes do processo de gestão, o que possibilita uma aproximação da gestão com os princípios da racionalidade substantiva (RAMOS, 1989). 


\section{Estrutura social das organizações}

A variável estrutura nos estudos organizacionais está presente desde as primeiras investigações, incluindo autores como Fayol, Taylor, Braverman e Barnard. A partir dos trabalhos de Max Weber sobre burocracia, aprimoraram-se as análises sobre estrutura, e nas décadas de 1960 e 1970, tais estudos dominaram o campo, com destaque especial para os trabalhos do grupo de Aston. Inspirados na teoria da contingência e incluindo novos elementos, surgiram trabalhos de destaque sobre estrutura, como as configurações estruturais propostas por Mintzberg (1995) e o trabalho clássico de Ranson, Hinnings e Greenwood (1980).

Se até meados da década de 1970 a organização era concebida como uma expressão da ação racional (SELZNICK, 1957), a partir desse ponto surgem novas abordagens teóricas que passam a explicar a estrutura como condicionada também pelo ambiente sociocultural ou institucional e não apenas pelo ambiente técnico (SCOTT, 1991). A teoria institucional, desenvolvida a partir de pesquisas em organizações públicas e sem fins lucrativos, trouxe novas questões para análise de uma multiplicidade de tipos organizacionais. Essa teoria resgatou de Weber a questão da legitimidade das estruturas administrativas e das ações organizacionais, ampliou o conceito de ambiente e recolocou o isomorfismo além da questão competitiva.

Numa concepção tradicional a estrutura é trabalhada apenas quanto às suas dimensões formais e os seus elementos como padronização, formalização, centralização/descentralização e dispersão espacial (HALL, 2004). Mintzberg (1995) vai definir a estrutura a partir dos seus mecanismos internos de coordenação e controle, tais como ajustamento mútuo, supervisão direta e padronização. Assim, não considera os mecanismos interorganizacionais de coordenação. Sua definição indica a estrutura como "a soma total das maneiras pelas quais o trabalho é dividido em tarefas distintas e como é feita a coordenação entre essas tarefas". Mintzberg (1995) afirma que:

os elementos de uma estrutura devem ser selecionados para alcançar uma congruência interna ou harmonia, bem como uma congruência básica com a situação da organização - suas dimensões $e$ idade, o tipo de ambiente no qual opera, o sistema técnico que utiliza, e assim por diante. (MINTZBERG, 1995, p.11)

Hatch (1997) define estrutura como os relacionamentos entre as partes de um todo organizado, incluindo então a parte física e social. A estrutura social - de maior interesse para este estudo - pode ser definida como os relacionamentos entre os elementos sociais, incluindo pessoas, posições e as unidades organizacionais às quais eles pertencem - departamentos, divisões etc. Abordagens mais dinâmicas sobre estruturas têm incluído a idéia de estruturação da estrutura e a possibilidade de construção de novas formas organizacionais. Nessa linha, a estrutura pode ser trabalhada como uma construção social que expressa os valores e expectativas de um grupo ou comunidade. Assim, rejeita a visão determinista de estrutura como resultante apenas das pressões do ambiente organizacional, mas também se evidencia o caráter limitante que a estrutura estabelece para a ação dos indivíduos. Em síntese, indica-se o conceito de estrutura como "um complexo meio de controle, o qual é continuamente produzido e recriado na interação, ainda que molde essa interação: estruturas são constituídas e constituintes." (RANSON, HINNINGS, GREENWOOD, 1980, p.3).

Situada nas abordagens mais dinâmicas e assumindo uma das novas formas organizacionais, encontra-se a configuração tipo redes - um sistema de nós e elos capaz de organizar pessoas e instituições de forma igualitária e democrática, na busca de um objetivo comum, tendo como fundamentos a autonomia, o compartilhamento de valores e objetivos, a conectividade entre indivíduo e organização, a participação, a descentralização e o dinamismo (TAKESHY, 2002). Constitui uma forma utilizada tanto para troca de informações como para a articulação política ou para a implementação de ações conjuntas.

Finalmente, faz-se importante ressaltar que a estrutura indica a distribuição de poder e também influencia a qualidade com que as atividades podem ser desenvolvidas. A estrutura deve ser pensada, então, dentro da sua capacidade de produzir resultados válidos numa perspectiva instrumental, mas fundamentalmente substantiva, quando se refere às organizações sociais. 


\section{Cultura organizacional, processo e construção}

As organizações são fenômenos complexos pela sua dinâmica e dependência do contexto onde estão inseridas. O ambiente - quando se considera suas dimensões sociais, culturais, políticas e técnicas - estabelece limites e oportunidades às organizações. O processo de globalização e as condições criadas para um maior nível de relações interculturais têm produzido situações ainda não bem compreendidas pelos analistas das organizações.

Nesse contexto, a cultura apresenta-se como um elemento-chave para entender como as organizações estão se transformando e como essas mudanças estão afetando a identidade das organizações e dos seus componentes. Neste artigo, a cultura é incluída como perspectiva para compreender as transformações e características das organizações sociais. Assim, partir-se-á de um conceito abrangente de cultura e de uma perspectiva que concebe a organização como uma construção social. O ambiente é interpretado também como uma construção, a qual, da forma como é construída na mente dos dirigentes, também vai determinar as concepções do que se entende por uma gestão adequada e sobre o papel que essas organizações devem desempenhar.

Cultura pode ser estudada a partir de diferentes perspectivas, pelas quais Smircich (1983) vai fazer referência à cultura como variável e à visão de cultura como metáfora. A segunda definição vai ao encontro dos pressupostos deste estudo ao pensar a cultura como uma construção coletiva. Hatch (1997) explica que os empregados constituem a principal influência sobre a cultura organizacional. Antes de entrarem para a organização, eles já foram influenciados por múltiplas instituições culturais como a família, a comunidade, a nação, o Estado, a Igreja, o sistema escolar e outras organizações. Essas instituições, por sua vez, vão moldar suas atitudes, comportamento e identidade. Assim, torna-se difícil separar a organização do sistema cultural mais amplo.

Um dos modelos mais aceitos para estudos empíricos de cultura é o modelo de Schein (HATCH, 1993). Segundo Hatch (1993), esse consiste em um arcabouço mais completo e explicativo para realização de estudos empíricos, embora apresente limitações, tais como partir de uma visão unitária de cultura e simplificar o fenômeno para facilitar sua apreensão. Na teoria de Schein, a cultura existe em três níveis: os artefatos presentes na superfície da cultura, abaixo dos artefatos estão os valores e as normas comportamentais e, mais profundamente, estão as crenças e pressupostos. Os artefatos são visíveis, mas normalmente não decifráveis, os valores e normas estão no nível da consciência e os pressupostos e crenças normalmente são invisíveis e aceitos inconscientemente.

A partir do conceito de Schein, ressalta-se a importância da cultura nos processos de mudança organizacional e nos desafios que se apresentam para as organizações quando da tentativa de mudanças deliberadas em sua gestão e características.

Um dos mitos ou símbolos que merecem destaque para o estudo de ONGs se refere à figura do fundador, cuja missão, idéias e exemplos são fios condutores de toda a gestão e manutenção das organizações sociais.

A cultura é moldada pelos valores, histórias, práticas e pela personalidade e visão do fundador ou líder principal. Os valores representam as bases da cultura fundamentando a filosofia da organização. As histórias são utilizadas para reforçar os princípios importantes, os mitos, lendas, ritos e rituais, suas tradições. Diante disso, a cultura é aprendida através da socialização e dos ensinamentos dos líderes, repercutindo no sucesso organizacional, na qualidade do trabalho e no ajuste entre pessoa e organização (DUBRIN, 2003).

Portanto, o líder torna-se um construtor da cultura organizacional, sendo o estabelecimento e manutenção da cultura um processo sistemático de criação e promoção - junto ao pessoal da organização - de relações baseadas na lealdade, confiança, vitalidade, participação, comunicação, valores e congruência de condutas (SOTO, 2002).

Neste estudo aceita-se os níveis de cultura propostos por Schein, mas se parte do entendimento de que a cultura não é unitária e não expressa unicamente a visão do líder. Nesse sentido, as mudanças nas ONGs devem tomar como base sua história, o líder, seus ritos e rituais e os seus artefatos, de forma a assegurar que não se produza 
uma crise de identidade e incoerência com a natureza do projeto social da organização. Isso exige elevado conhecimento das bases de sustentação da organização, além do mero conhecimento das técnicas de gestão.

\section{Metodologia}

Este artigo resultou de uma pesquisa que adotou como procedimento metodológico o estudo multicaso e a tipologia descritiva exploratória de pesquisa, com uma perspectiva de análise predominantemente qualitativa.

A pesquisa qualitativa, segundo Triviños (1997), "procura uma espécie de representatividade do grupo maior dos sujeitos que participarão do estudo". Por isso, a amostra desta pesquisa é constituída por organizações representativas da sua área de atuação. Foram analisadas 10 ONGs em Natal (RN), incluindo diferentes segmentos de atuação (quadro 1). Para seleção dos casos, adotou-se como critérios: a existência superior a dois anos de fundação; atuação na área de desenvolvimento comunitário, social ou econômico (geração de renda) e enquadramento como tipologias de associações, ONGs, grupo comunitário ou social. Por questão de sigilo, os nomes originais foram substituídos por nomes de deuses da mitologia grega. Constituíram o objeto de estudo desta pesquisa:

Quadro 1

ONGs participantes da pesquisa

\begin{tabular}{ll}
\hline ONG & ATUAÇÃO \\
\hline Hera & Apoio a iniciativas da economia solidária \\
\hline Artemis & Educação de meninos de rua através da arte-educação \\
\hline Héstia & Acolhimento de crianças \\
\hline Zeus & Apoio a vítimas de violência e abuso sexual \\
\hline Ares & Apoio e desenvolvimento urbano para comunidades carentes \\
\hline Afrodite & Promoção, organização e incentivo ao voluntariado \\
\hline Apolo & Assistência a portadores de deficiência física \\
\hline Atena & Apoio à criança com câncer \\
\hline Hermes & Apoio à adoção \\
\hline Poseidon & Educação e despertar da cidadania de crianças \\
\hline
\end{tabular}

Fonte: dados da pesquisa

Os dados utilizados na pesquisa foram coletados pelos pesquisadores a partir de entrevistas semi-estruturadas, utilizando roteiro de entrevistas. As entrevistas tiveram duração média de 80 minutos, foram gravadas e posteriormente transcritas. O número de entrevistados variou entre duas e quatro pessoas por organização estudada, dependendo da estrutura da mesma. Foi utilizada também análise de documentos produzidos pelas organizações, como prospectos e informativos elaborados pelas ONGs para fins de divulgação ou captação de recursos; documentos contendo missão, valores e objetivos das organizações; organogramas existentes em algumas ONGs; planejamentos; projetos desenvolvidos e histórico institucional.

A análise das informações transcritas, assim como dos documentos encontrados nas organizações foi conduzida a partir dos componentes estudados - estrutura e cultura - por organização, possibilitando a elaboração do quadro de resultados (quadro 2). Documentos analisados proporcionaram condições de verificar alguns componentes estruturais das ONGs e em alguns casos, os culturais - valores, normas comportamentais e crenças.

\section{Análise e discussão dos resultados}

Os resultados da pesquisa são apresentados e analisados por componente estudado, a princípio, através de uma síntese dos dados, depois, por meio da descrição de aspectos relevantes e característicos de algumas das organi- 
zações estudadas, considerando o referencial adotado no sentido de mostrar a existência ou não de congruências com o que se espera de uma ONG.

\section{Estrutura social}

Com relação à estrutura organizacional, foram encontradas ONGs com baixíssimo grau de formalização e outras altamente formalizadas, sendo constatado um alto grau de variação. Seguindo as perspectivas de estudos de Hall (2004) e Mintzberg (1995), algumas das organizações apresentam divisão de funções característica das organizações tradicionais, mas a maioria trabalha com a multifuncionalidade e com estruturas configuradas segundo os projetos em desenvolvimento, conforme colocado por Mello, Fischer e Soares Jr. (2003). Quando a estrutura se assemelha à das organizações tradicionais, é formalizada através de organograma; nas demais, não há tipo algum de descrição ou representação.

Apesar da maioria das organizações apresentar estrutura mais flexível, a concepção da divisão do trabalho é tão arraigada que a multifuncionalidade é considerada uma deficiência na gestão e no quadro de pessoal da organização. Com isso, constata-se que o tradicional e o formal são corretos; o novo e informal, incorretos.

Entre as ONGs pesquisadas, quatro têm organograma formalizado, expressando em sua maioria uma estrutura simples e com poucos níveis hierárquicos, e seis não apresentam estrutura formalizada. Aproximadamente, metade destas têm problemas com a definição e desempenho de funções e problemas na estrutura organizacional. Esses dados corroboram o que se espera desse tipo de organização com relação à redução de níveis hierárquicos e flexibilidade (MATTOS; DINIZ, 2002; MARÇON; ESCRIVÃO FILHO, 2001; ROESCH, 2002). Naquelas organizações que possuem estrutura formalizada, isso não significa que o estabelecido esteja sendo seguido nem que reflita a realidade das organizações, mas reflete uma tentativa de aproximar-se do que a administração entende como uma organização "bem estruturada", ou seja, o formalismo corresponde à organização e à profissionalização, segundo os dirigentes das ONGs.

Tanto essa concepção de formalização quanto à da multifuncionalidade refletem incongruências na gestão dessas organizações. Podem ser explicadas pelas pressões exercidas pelo ambiente quando se estabelece o que deve ser aceito como correto e necessário para a sobrevivência organizacional (MEYER; ROWAN, 1991; POWELL; DIMAGGIO, 1991). Esses resultados indicam também que a falta de formalização não reflete a consciência da construção da estrutura como processo coletivo e social (HATCH, 1997), demonstrando que essas organizações ainda encontram-se distantes do tipo de visão de estrutura mais adequado às suas especificidades.

Diante da grande variedade de resultados, optou-se por destacar a descrição de algumas organizações por mostrarem congruências e/ou incongruências com aquilo que se espera de uma organização social, com relação a sua estrutura.

A ONG Zeus não estabelece organograma, considerando-o um instrumento dispensável. Existe uma relação das funções (entre 30 e 40) a serem desempenhadas pelos integrantes, a depender dos projetos desenvolvidos, o que reflete a multifuncionalidade e uma forte integração entre os setores. A ausência da formalização da estrutura e funções não leva a resultados insatisfatórios para a organização, que trabalha através da integração e interação constantes, através de assembléias e reuniões com periodicidade definida. A responsabilidade pela gestão institucional é da coordenação colegiada, composta por membros escolhidos através de um processo democrático e participativo.

A ONG Artemis apresenta uma estrutura simples, não formalizada, mas com funções e responsabilidades bem definidas e conhecidas pelos colaboradores através do processo de conscientização. A maioria dos colaboradores dessa ONG é de pessoal voluntário.

Diante desses resultados, é possível considerar que as ONGs Zeus e Artemis correspondem ao que se espera quanto às particularidades estruturais e culturais da gestão de organizações sociais identificadas pelos estudos 
de Marçon e Filho (2001), Meira e Rocha (2003), Mello, Fischer e Soares Jr. (2003), Roesch (2002), Takeshy (2002) e Tenório (2001).

Outro aspecto do desenho da estrutura considerado significativo se refere à formalização e padronização de processos (HALL, 2004; MINTZBERG, 1995). A padronização foi instrumento encontrado em cinco ONGs estudadas. Constituem rotinas e procedimentos dos principais fluxos de trabalho, ou seja, aqueles voltados ao atendimento do público ou comunidade. A inexistência da formalização em algumas organizações pesquisadas não reflete desorganização nem desconhecimento do fluxo de trabalho por parte dos seus realizadores, ressaltando o envolvimento, a comunicação, participação e compartilhamento de informações (MEIRA; ROCHA, 2003; TEODÓSIO, 2001) e a ação negociada (MARÇON; ESCRIVÃO FILHO, 2001).

Na ONG Zeus, os seus membros reconhecem que a presença da formalização de alguns aspectos - como procedimentos - é necessária, mas que estes não são fatores que impedem a existência da autonomia e da participação. Resultados indicam que pode haver elementos instrumentais de controle, mas com dinâmica organizacional fundamentada na racionalidade substantiva (MEIRA; ROCHA, 2003).

Na ONG Atena existem normas e procedimentos formalizados e expostos em mural, porém estes não são praticados. As ONGs se esforçam no sentido de definirem e elaborarem seus padrões, muitas vezes, até investem recursos para a profissionalização e, à medida que fazem isso, distanciam-se do caráter dinâmico e integrativo, intrínseco à gestão de organizações sociais. Isso ocorre, muitas vezes, quando essas organizações contratam consultorias que trabalham a partir de um referencial e técnicas de gestão pautados por valores de mercado, orientados para resultado econômico.

A ONG Apolo possui manuais e documentos onde são definidos os procedimentos e a divisão formal do trabalho, aspectos destacados pelos dirigentes, mas que não condizem com depoimentos dos colaboradores quanto ao seu conhecimento ou utilização. Essa organização apresenta incongruência no que se espera quanto à construção coletiva, comunicação e entendimento.

Esses resultados, em sua maioria, demonstram a existência de uma contínua interação, o que permite afirmar que a análise das organizações sociais deve ser realizada com base em perspectivas que compreendam a estrutura como uma construção coletiva e dinâmica (RANSON, HINNINGS, GREENWOOD, 1980), considerando os relacionamentos entre as pessoas, a posição que ocupam (HATCH, 1997) e a função que exercem no momento. A teoria organizacional tradicional não dispõe de subsídios capazes de explicar de modo coerente a dinâmica inerente às ONGs.

A estrutura reflete a centralização ou descentralização do poder. Em quatro organizações estudadas, há descentralização do poder, três apresentam centralização e dependência do detentor do poder, normalmente, fundador ou o principal gestor da ONG onde foi detectado o autoritarismo. Nas três restantes, constatou-se que as principais definições são centralizadas, mas que há também distribuição do poder e participação, abertura, liberdade para expor sentimentos, sugestões e opiniões. Pode-se afirmar que esses aspectos se aproximam das descentralizadas quando todas afirmam que a presença dos fundadores ou presidentes é muito forte e respeitada, mas não caracterizada como autoritária. Por isso, é possível concluir que a grande maioria das ONGs apresenta congruência com o que se espera quanto ao processo decisório participativo (ROESCH, 2002; TAKESHY, 2002; TENÓRIO, 2003), ação negociada (MARÇON; ESCRIVÃO FILHO, 2001) e ao debate interno (MEIRA; ROCHA, 2003).

Na ONG Atena, o poder e as decisões são centralizados nas mãos do presidente, que promove a participação nas decisões somente quando não consegue solucionar isoladamente os problemas. Os voluntários e contratados reclamam da centralização e sentem-se incapazes. Já na ONG Hera, a gestão é participativa e os colaboradores têm autonomia para a indicação de projetos nos quais a ONG deve atuar, para expor opiniões durante as assembléias.

O debate interno e a participação são evidentes na ONG Zeus, uma das ONGs estudadas que apresenta um grande número das características relacionadas pelos autores que têm realizado pesquisas sobre gestão de 
ONGs. Nessa organização, todas as decisões são colegiadas, há reuniões freqüentes de acompanhamento, autonomia dos indivíduos no desempenho das suas atividades e na exposição dos seus argumentos e, como conseqüência, um maior engajamento no trabalho.

Na ONG Ares há centralização de poder por parte da coordenação geral, existem relações de dominação e manipulação, numa situação de extrema centralização na tomada de decisão e execução. Há autoritarismo, não há trabalho em equipe e há concentração de todos os tipos de recursos.

Na ONG Afrodite, a liderança é considerada democrática e participativa, buscando, para a tomada de decisões, conhecer antes as opiniões de sua equipe, para assim fazer as melhores escolhas. Apesar da democracia existente, o fundador ainda é o único responsável pela ONG e muitas decisões não podem ser tomadas por outro colaborador. O mesmo acontece na ONG Artemis, onde há centralização por parte da presidência, porém há repasse contínuo de informações, reuniões mensais de planejamento e avaliação e tratamento de todos os assuntos a respeito da instituição, onde há participação de todos os voluntários e todos têm liberdade de expor suas opiniões. Mais uma vez fica evidente a coexistência de aspectos de racionalidades distintas, mas com predomínio da substantiva, mais próxima à realidade das ONGs.

Em se tratando de estrutura organizacional, verificou-se que as organizações estudadas, em sua maioria, utilizam conceitos, modelos e instrumentos oriundos da teoria organizacional tradicional, mas funcionam segundo uma racionalidade que se apresenta incongruente com os mesmos. Na busca pela profissionalização, essas organizações procuram adotar o que é dito como correto para administrar e, com isso, sepultam aspectos da sua própria essência.

Assim, a explicação sugerida por Scott (1991) se aplica às organizações em estudo: estrutura condicionada não somente pelo ambiente técnico, mas também pelo sociocultural ou institucional. O caráter dinâmico, integrativo e mutável dessas organizações explica a complexidade desse meio de controle organizacional (RANSON, HINNINGS E GREENWOOD, 1980), produzido e recriado na interação pela qual molda e é moldado.

As novas formas organizacionais, como as redes, são mais coerentes com o desenho da estrutura das organizações sociais, pois comportam e consideram elementos como autonomia, o compartilhamento de valores, objetivos e informações, a conectividade entre indivíduo e organização, a participação, a descentralização e o dinamismo (TAKESHY, 2002), sendo condizentes também com a compreensão dos relacionamentos interorganizacionais, tão comuns nessas organizações (MELLO; FISCHER; SOARES JR, 2003), permeados de aspectos políticos e culturais.

Os resultados sobre a estrutura confirmam a possibilidade colocada por Brum, Assis e Costa (2004) quanto ao fato dessas organizações estarem trabalhando de forma equivocada, quando se trata de estrutura organizacional diante da sua realidade e do ambiente onde atuam.

Foi possível identificar também que pode ocorrer a adoção do funcionalismo bem sucedido, conforme verificado por Meira e Rocha (2003), desde que para a implantação exista amplo processo de avaliação e debate interno com participação e envolvimento das pessoas. Pinheiro (2003) ressalta que a administração deve compreender os elementos sociais como partes do processo de gestão, que deve ser guiado por elementos da racionalidade substantiva.

Conforme demonstrado nos resultados, as organizações sociais são mais informais, mais flexíveis e têm melhor capacidade de integração e envolvimento de pessoal devido à identificação com a missão institucional e com os processos de trabalho da instituição. São organizações que conseguem atingir seus objetivos sem necessariamente utilizar modelos, técnicas e o excesso de formalização tão presente nas organizações tradicionais. Ficou evidente também que muitas vezes, quando os utilizam, há uma tendência a "engessar" o processo ou a acumular papéis e expor quadros que não refletem sua realidade. 


\begin{tabular}{|c|c|c|}
\hline \multicolumn{3}{|c|}{$\begin{array}{c}\text { Quadro } 2 \\
\text { Componentes estruturais e culturais das ONGs estudadas }\end{array}$} \\
\hline ONG & ESTRUTURA SOCIAL & CULTURA \\
\hline Hera & $\begin{array}{l}\text { Descentralizada, segue as interações } \\
\text { sociais e os projetos em desenvolvimento. }\end{array}$ & $\begin{array}{l}\text { Clima amistoso onde predomina a } \\
\text { autonomia. } \\
\text { Fundador como motivador e orientador. }\end{array}$ \\
\hline Artemis & $\begin{array}{l}\text { Simples, flexível, não formalizada e tem } \\
\text { base nas interações sociais. Alto grau de } \\
\text { participação. }\end{array}$ & $\begin{array}{l}\text { O fundador é a alma do projeto social, } \\
\text { levando à conscientização e ao } \\
\text { comprometimento, liberdade. }\end{array}$ \\
\hline Héstia & $\begin{array}{l}\text { Alto grau de informalidade e } \\
\text { centralização. Tendência de relações } \\
\text { autoritárias. }\end{array}$ & $\begin{array}{l}\text { Imagem do fundador é a única referência da } \\
\text { instituição, apesar de atualmente estar } \\
\text { distante da gestão. }\end{array}$ \\
\hline Zeus & $\begin{array}{l}\text { Flexível e dinâmica. Tem base nas } \\
\text { interações. Configurada de acordo com os } \\
\text { projetos desenvolvidos. Forte integração } \\
\text { entre áreas. }\end{array}$ & $\begin{array}{l}\text { Valores com foco em resultados, mas há } \\
\text { alto grau de identidade e satisfação. } \\
\text { Fundador como disseminador do } \\
\text { comprometimento. }\end{array}$ \\
\hline Ares & $\begin{array}{l}\text { Formalizada, centralizada, com relações } \\
\text { predominantemente autoritárias. Falta de } \\
\text { integração. }\end{array}$ & $\begin{array}{l}\text { Valores proclamados pela gestão diferentes } \\
\text { dos percebidos pelos colaboradores. } \\
\text { Fundador é figurativo. }\end{array}$ \\
\hline Afrodite & $\begin{array}{l}\text { Centralização de algumas decisões, mas } \\
\text { há participação e abertura no processo de } \\
\text { comunicação. }\end{array}$ & $\begin{array}{l}\text { Fundador determinante em todas as } \\
\text { atividades, mas há comprometimento e } \\
\text { motivação. }\end{array}$ \\
\hline Apolo & $\begin{array}{l}\text { Formalização que não condiz com a } \\
\text { realidade organizacional. }\end{array}$ & $\begin{array}{l}\text { Cultura impulsionada pela missão social. } \\
\text { Fundador é considerado exemplo a ser } \\
\text { seguido. }\end{array}$ \\
\hline Atena & $\begin{array}{l}\text { Centralizada, apresenta formalização que } \\
\text { não condiz com realidade. }\end{array}$ & $\begin{array}{l}\text { Valores definidos não correspondem aos } \\
\text { praticados e o clima não se apresenta } \\
\text { agradável. }\end{array}$ \\
\hline Hermes & $\begin{array}{l}\text { Informalidade. Segue interações } \\
\text { necessárias a cada projeto. }\end{array}$ & $\begin{array}{l}\text { Solidariedade e falta de continuidade nos } \\
\text { projetos desenvolvidos. }\end{array}$ \\
\hline Poseidon & $\begin{array}{l}\text { Há centralização de decisões principais. É } \\
\text { formalizada, mas também participativa e } \\
\text { dinâmica. }\end{array}$ & $\begin{array}{l}\text { Valoriza o profissionalismo, o } \\
\text { compromisso social e a solidariedade }\end{array}$ \\
\hline
\end{tabular}

Fonte: dados da pesquisa

É importante esclarecer que três das 10 organizações pesquisadas não apresentaram resultados com significados suficientemente relevantes para que fossem incluídas na análise realizada, apesar de constarem no quadro.

\section{Cultura organizacional}

Os valores, normas comportamentais, crenças e pressupostos (HATCH, 1993) que instituem a cultura refletem a racionalidade subjacente ao processo de gestão, permitindo identificar se há congruência entre o estilo de gestão que se pratica na organização e o que se espera dela. Na maioria das ONGs estudadas, a racionalidade substantiva permeia grande parte dos aspectos culturais, apresentando assim um alto grau de congruência com o que se espera das organizações sociais.

Entre as ONGs pesquisadas, cinco têm formalmente definidas missão e valores. Mas isso não significa necessariamente que eles reflitam a realidade das organizações estudadas, pois há alguns casos em que a missão é definida e não é conhecida por todos. Também verificou-se contradições sobre os valores dominantes, que variavam seguindo a posição ocupada na ONG ou o tempo de atuação da pessoa na mesma. Isso aconteceu numa minoria das organizações, mas reflete incongruência entre discurso e prática. 
Na maioria das ONGs, os elementos da cultura - principalmente os valores - são percebidos de forma semelhante e sincronizada pelos entrevistados, mesmo que nunca tenham sido explicitados pelos gestores. Há o conhecimento e o compromisso com a missão, sem que esta esteja necessariamente formulada e publicada ou tenha sido definida segundo os meios do planejamento convencional. Isso se deve ao processo de socialização que proporciona o aprendizado (DUBRIN, 2003) e a internalização da cultura organizacional por parte dos seus colaboradores e voluntários, repercutindo no sucesso da instituição.

Fica evidente, então, que não é necessário que as ONGs incorporem indiscriminadamente técnicas e modelos da administração tradicional, mas construam sua própria dinâmica organizacional. Também fica claro que a cultura organizacional e as formas de interação social são fatores que possibilitam a sustentação, manutenção e recriação constante da estrutura, refletindo na concretização do projeto social dessas organizações.

Foi constatado na pesquisa, que o líder é o construtor da cultura organizacional, sendo o estabelecimento e manutenção da cultura, um processo sistemático de criação e promoção - junto ao pessoal da organização - de relações baseadas na lealdade, confiança, vitalidade, participação, comunicação, valores e congruência de condutas (SOTO, 2002).

Nas ONGs pesquisadas, a cultura organizacional está diretamente relacionada à figura dos fundadores, que mesmo quando não se encontram mais presentes no cotidiano da instituição, exercem forte influência. No processo de construção da cultura, o fundador é fator determinante cujos resultados de atuação repercutirão no sucesso ou fracasso da missão institucional. Verificou-se que além da presença do líder, também são importantes para os resultados e a legitimidade dessas organizações as intenções determinantes durante o processo de fundação e o nível educacional dos fundadores, dirigentes principais ou voluntários. Portanto, a cultura é moldada pelos valores, práticas, pela personalidade e visão do fundador (DUBRIN, 2003).

$\mathrm{Na}$ ONG Artemis, foi verificado que na figura do fundador encontra-se a alma do projeto social e que sua influência nas pessoas torna o grupo coeso, compartilhando o mesmo ideal e sem divergências. Os valores organizacionais encontram-se diretamente relacionados com aqueles necessários à promoção e manutenção do projeto social da organização: comprometimento com liberdade, respeito à individualidade e reciprocidade (relação de troca não instrumental). O fato da ONG Artemis possuir apenas voluntários em seu quadro contribuiu para a manutenção dos bons relacionamentos, pois todos estão unidos em torno de um mesmo objetivo e possuem os mesmos interesses, ou seja, a causa do projeto.

Na ONG Zeus também há forte presença do fundador, apesar de não ser parte do quadro da direção atual. Compromisso e comprometimento com a causa são aspectos destacados.

A Ares foi a única ONG que apresentou incongruência com o que se espera com relação ao fundador e também a respeito da construção da cultura. A presidência é sempre assumida por um religioso. A figura do fundador ou presidente representa função meramente burocrática e figurativa e os valores proclamados como dominantes contradizem o que foi verificado na prática, a partir do sentimento dos participantes.

Com relação aos valores e crenças estabelecidos pela gestão, na ONG Zeus, estes estão relacionados com resultados - alcance de metas, qualificação, especialização e valorização da instituição perante o mercado. Foi verificado também, através da fala de participantes, que todos os projetos da casa são projetos de vida, de realização pessoal, onde o trabalho desenvolvido é visto como um instrumento de vida para cada pessoa, o que proporciona satisfação em "saber que se contribuiu para a construção de pessoas felizes por terem superado seus problemas". Ficou evidente nessa ONG que o conteúdo do trabalho é visto como significativo e rico pelos participantes, garantindo o envolvimento. No entanto, resultados melhores poderiam ser alcançados, se a forma como a atividade é conduzida propiciasse condições de participação e atualização dos atores envolvidos.

Os valores originais típicos das organizações sociais - altruísmo, promoção social, ajuda mútua, compaixão, voluntarismo, sensibilidade, solidariedade e o direito à livre expressão e organização - (ROESCH, 2002) foram encontrados na maior parte das organizações pesquisadas. Na única onde apareceram termos instrumentais en- 
tre os valores, esse aspecto foi destacado pelos seus próprios participantes mais como uma preocupação com resultados que uma substituição por valores de mercado.

A disseminação da cultura organizacional pode ser refletida através do clima organizacional. Nas ONGs, constatou-se que o clima organizacional está associado ao estilo de liderança, a quem detém e exerce poder. Quanto mais centralizado o estilo de gestão, mais negativo é o clima organizacional e menor o nível de motivação do pessoal.

Na ONG Hera, o clima verificado foi amigável e o pessoal foi caracterizado como "sorridente, feliz e satisfeito". Na ONG Apolo, o clima e cultura são impulsionadores para a realização das atividades e a figura do fundador é marcante e associada a uma atuação exemplar e contínua.

É importante ressaltar que uma das organizações que apresenta centralização de algumas decisões revela também características da gestão participativa e clima organizacional positivo, pois outras decisões e toda a condução do trabalho são realizadas de forma compartilhada. Nas ONGs onde há forte centralização, o clima organizacional não se revela positivo.

Os resultados indicam que prevalecem nas ONGs estudadas a comunicação aberta e fluída, a participação e o envolvimento dos colaboradores. A cultura aparece, portanto, como uma construção coletiva onde colaboradores exercem forte influência (HATCH, 1997), já que através deles se desenvolvem os processos de disseminação e socialização.

As particularidades das organizações sociais conforme verificadas - participação ampla, processo decisório participativo, cultura organizacional disseminada, presença da autonomia e satisfação - (ANDION, 2005; MARÇON; ESCRIVÃO FILHO, 2001; MELO; FISCHER; SOARES JÚNIOR, 2003; TENÓRIO, 2001) são conseqüências de uma dinâmica diferente de gestão, onde a estrutura não segue os moldes tradicionais e se aproxima daquelas mais modernas e flexíveis, onde a cultura é elemento fundamental para a coesão e o sucesso organizacional.

Foram constatadas e confirmadas a diversidade e as especificidades identificadas pelos autores tomados como referências neste estudo. Há congruência entre o que espera e o que se encontrou na maioria das ONGs com relação à cultura organizacional e sua importância na compreensão das características das organizações sociais. Os valores dominantes nas organizações sociais também foram identificados nos resultados. Mas com relação à estrutura, existem incongruências - poucas, com relação ao que se espera, no que concerne à construção e desenvolvimento da dinâmica organizacional, mas muitas quando se trata de conceitos, modelos e técnicas utilizados na gestão, no sentido de promover a estruturação, a coordenação e o controle do trabalho. A dinâmica existente e a racionalidade que a guia se mostraram incongruentes com os meios administrativos identificados, copiados e utilizados sem uma devida avaliação crítica ou contextualização para a realidade das organizações sociais.

\section{Conclusões e recomendações}

Os resultados encontrados proporcionaram respostas para a questão de estudo proposta, identificando as particularidades referentes aos aspectos culturais e estruturais das organizações sociais e indicando a existência ou não de congruência destes com relação às expectativas da gestão dessas organizações, cumprindo assim o objetivo a que se propôs.

Este estudo faz uma análise crítica dos componentes estruturais e culturais das ONGs, indo além da descrição das práticas e desafios da sua gestão. Revelando-se, portanto, de particular importância para a compreensão de incongruências intrincadas no processo de gestão das organizações sociais, principalmente, no que diz respeito à utilização de pressupostos teóricos e de práticas de tecnologias desenvolvidas para organizações convencionais, guiadas pela racionalidade instrumental. 
Nesse sentido, reflete um avanço ao pensar a gestão dessas organizações a partir de práticas da sua própria realidade e demonstrar que as teorias organizacionais tradicionais não são as mais indicadas para a análise dessas organizações. Isso, devido à racionalidade subjacente aos estudos tradicionais entrar, muitas vezes, em contradição com a dinâmica organizacional das organizações sociais. É, portanto, um passo no sentido de contribuir para a construção de um modelo alternativo de gestão, conforme citado por Andion (2005), Meira e Rocha (2003), Tenório (2003), Teodósio (2001) e Serva (1996), guiado por uma racionalidade mais próxima à substantiva apresentada por Ramos (1989).

É imprescindível considerar a realidade nacional e/ou regional, e também as características originais e inerentes ao caráter social das ONGs, para a configuração de um modelo de gestão próprio que responda às especificidades da organização, tanto tecnicamente - tipo de público atendido, prazo de desenvolvimento dos projetos e pessoal necessário - quanto de modo substantivo - flexibilidade, valorização de aspectos culturais, comunicação fluída, participação e integração.

Representa um avanço ao demonstrar que as organizações sociais proporcionam subsídios suficientes para o desenvolvimento de um arcabouço teórico mais específico para a sua realidade e para a realidade do país ou região onde se situa, num espaço de intermediação entre o público e o privado.

Finalmente, recoloca-se a idéia de construção de um arcabouço multidisciplinar para pensar a gestão das organizações sociais, fazendo-se uma ponte com o que existe de avanços nos estudos organizacionais, com o dinamismo e a capacidade criativa dessas organizações. É importante ressaltar que o desenvolvimento de estudos deve ter como base a realidade das organizações não-governamentais nacionais, que se diferenciam das americanas e européias por um conjunto de fatores que incluem o contexto político e histórico, a realidade econômica, social e aspectos culturais, presentes desde o momento do surgimento até a configuração do processo de profissionalização dessas organizações no Brasil, e de forma semelhante em alguns países da América Latina.

Essa área carece não somente de modelos teóricos para sua compreensão, mas também de construção de estratégias alinhadas com uma visão de projeto que coloca o homem, a sociedade, a natureza e a realidade na qual se encontra inserida cada organização como realmente centros direcionadores das práticas organizacionais no cotidiano da gestão. Isso implica retomar temas como ética, racionalidade substantiva, bem comum, cidadania e alienação na perspectiva dos práticos e dos teóricos responsáveis pelas atividades das organizações sociais.

Como a pesquisa se limitou a estudar os aspectos estrutura social e cultura organizacional, recomenda-se que novos estudos sejam realizados com relação a esses componentes, no sentido de aprofundar e de possibilitar uma ampliação do quadro de organizações estudadas, mas principalmente no que se refere aos outros aspectos de gestão dessas organizações, como comunicação, poder e processo decisório. É importante também que sejam conduzidos novos estudos a partir de teorias fundamentadas nos aspectos sociais, culturais e simbólicos das organizações. 


\section{Referências}

ANDION, C. A gestão no campo da economia solidária: particularidades e desafios. Revista de Administração Contemporânea, v. 9, n.1, 2005.

BRASIL. Instituto Brasileiro de Geografia e Estatística. As fundações privadas e associações sem fins lucrativos no Brasil. Disponivel em: <www.ibge.gov.br/home/estatistica/economia/fasfil/default.shtm>. Acesso: 14 jan. 2005.

BRUM, M. R.; ASSIS, L. B.; COSTA G. A. Análise da relação entre a estrutura e a estratégia: estudo de casos em organizações do terceiro setor de Minas Gerais. In: ENCONTRO ANUAL DA ASSOCIAÇÃO NACIONAL DE PÓS-GRADUAÇÃO EM ADMINISTRAÇÃO, 28., Curitiba. Anais... Curitiba: Anpad, 2004.

DUBRIN. Fundamentos do comportamento organizacional. São Paulo: Pioneira, 2003.

HALL, R. Organizações: estruturas, processos e resultados. 8.ed. São Paulo: Prentice Hall, 2004.

HATCH, M. J. The dynamics of organizational culture. Academy of Management Review, v.18, n.4, 1993.

Organization theory: modern, symbolic and postmodern perspectives. Oxford: Oxford University Press, 1997.

HUDSON, M. Administrando organizações do terceiro setor: o desafio de administrar sem receita. São Paulo: Makron Books, 1999.

MARÇON, D.; ESCRIVÃO FILHO, E.. Gestão de organizações do terceiro setor: um repensar sobre as teorias organizacionais. In: ENCONTRO ANUAL DA ASSOCIAÇÃO NACIONAL DO PROGRAMAS DE PÓS-GRADUAÇÃO EM ADMINISTRAÇÃO, 25., Campinas, SP. Anais... Campinas: Anpad, 2001.

MATTOS, P. L. C. L.; DINIZ, J. H. A L. Organizações não-governamentais e gestão estratégica: desfiguração do seu caráter institucional original? In: ENCONTRO ANUAL DA ASSOCIAÇÃO NACIONAL DOS PROGRAMAS DE PÓS-GRADUAÇÃO EM ADMINISTRAÇÃO, 26., Salvador, BA. Anais... Salvador: Anpad, 2002.

MEIRA, L. C. C.; ROCHA, G. S. Modelos de gestão de ONGs ambientalistas: um estudo comparativo em três organizações baianas. In: ENCONTRO ANUAL DA ASSOCIAÇÃO NACIONAL DOS PROGRAMAS DE PÓS-GRADUAÇÃO EM ADMINISTRAÇÃO, 27., Atibaia, SP. Anais... Atibaia: Anpad, 2003.

MELO, V. P., FISCHER, T.; SOARES JR, J. S. Diversidades e confluências no campo do terceiro setor: um estudo em organizações baianas. In: XXVII Encontro Nacional da Associação Nacional dos Programas de Pós-Graduação em Administração. Atibaia/SP. Anais... Atibaia, SP, ANPAD, 2003.

MENDES, L. C. A. Para onde vão as ONGs? De assessorias informais de apoio a organizações profissionais estruturadas. Brasília, 1997. Dissertação (Mestrado) - Universidade de Brasilia.

MEYER, J.; ROWAN, B. Institutionalized organizations: formal structure as myth and ceremony. In: POWELL, W.; DIMAGGIO, P. (Ed.) The new institutionalism in organizational analysis. Chicago: Chicago University Press, 1991.

MINTZBERG, H. Criando organizações eficazes: estruturas em cinco configurações. São Paulo: Atlas, 1995.

PINHEIRO, D. M. Sustentabilidade de ONGs: um estudo de caso na Acef - Associação Franciscana de Educação ao Cidadão Especial. Curitiba, 2003. Dissertação (Mestrado) - Universidade Federal do Paraná.

POWELL, W.; DIMAGGIO, P. (Ed.) The new institutionalism in organizational analysis. Chicago: Chicago University Press, 1991.

RAMOS, A. G. A nova ciência das organizações. 2.ed. Rio de Janeiro: Editora da Fundação Getulio Vargas, 1989.

RANSON, S.; HINNINGS, B.; GREENWOOD, R. The structuring of organizational structures. Administrative Science Quarterly, v.25, 1980.

ROESCH, S. Gestão de ONGs: rumo a uma agenda de pesquisas que contemple a sua diversidade. In: ENCONTRO ANUAL DA ASSOCIAÇÃO NACIONAL DOS PROGRAMAS DE PÓS-GRADUAÇÃO EM ADMINISTRAÇÃO, 26., Salvador, BA. Anais... Salvador: Anpad, 2002. 
SCOT, W. R. Unpacking institutional arguments. In: POWELL, W.; DIMAGGIO, P. (Ed.) The new institutionalism in organizational analysis. Chicago: Chicago University Press, 1991.

SELZNICK, P. Leadership in administration. New York: Harper and Row, 1957.

SERVA, M. Racionalidade e organizações: o fenômeno das organizações substantivas. São Paulo: FGV/Eaesp, 1996. Tese (Doutorado) Fundação Getúlio Vargas.

SMIRCICH, L. Concept of culture and organizational analysis. Administrative Science Quarterly, v.28 n.3, 1983.

SOTO, E. Comportamento organizacional: o impacto das emoções. São Paulo: Pioneira, 2002.

TAKESHY, T. ONGs e terceiro setor: criação de ONGs e estratégias de atuação. São Paulo: Atlas, 2002.

TENÓRIO, F. G. Gestão de ONGs: principais funções gerenciais. 7.ed. Rio de Janeiro: Fundação Getulio Vargas, 2003.

TEODÓSIO, A. S. S. Pensar o terceiro setor pelo avesso: dilemas e perspectivas da Ação social organizada na gestão pública. In: ENCONTRO ANUAL DA ASSOCIAÇÃO NACIONAL DOS PROGRAMAS DE PÓS-GRADUAÇÃO EM ADMINISTRAÇÃO, 25., Campinas, SP. Anais... Campinas: Anpad, 2001.

TRIVIÑOS, A. N. S. A pesquisa qualitativa em educação: o positivismo, a fenomenologia, o marxismo. São Paulo: Atlas, 1997. 